\title{
Learning to See Clear: Quantification and Multidimensional Assessment of Value Stream Mapping Alternatives Considering Variability
}

\author{
Markus P. Roessler ${ }^{1}$, Joachim Metternich ${ }^{1} \&$ Eberhard Abele $^{1}$ \\ ${ }^{1}$ Institute of Production Management, Technology and Machine Tools, Technical University Darmstadt, Germany \\ Correspondence: Markus P. Roessler, Institute of Production Management, Technology and Machine Tools (PTW), \\ Technical University Darmstadt, 64287 Darmstadt, Germany. Tel: 49-(0)6151-16-75659. E-mail: mp.roe@web.de
}

Received: May 7, 2014

doi:10.5430/bmr.v3n2p93
Accepted: June 10, 2014

Online Published: June 12, 2014

\begin{abstract}
The prior quantification and validation of future state maps in lean production and optimization projects mostly is not taken into consideration in the traditional value stream mapping approaches. Furthermore the implementation of future states is based upon the trial and error principle. The effects of proactively changing production systems often are unknown and could underlie vast variations due to the planned outcome. So for many managers hard facts are missing and the uncertainties included in such a value stream optimization project are very high. This prevents a necessary system change accompanied by the adoption of lean methods. Thus in this paper a comprehensive value stream optimization approach is presented which primarily focuses upon chances for prior static and dynamic future state map quantification. Under consideration of parameter variability a downstream multidimensional assessment of possible design alternatives is proposed using a fuzzy decision making method to facilitate transparency in the selection of the most adequate future state map. The method described in this paper will be discussed at an industrial case study.
\end{abstract}

Keywords: Lean production, Value stream mapping, Quantification, Performance management, Variability, Fuzzy multi-criteria decision analysis

\section{Introduction}

\subsection{Background and relevance}

Due to shorter product lifecycles and rising numbers of product variants today's manufacturing industry faces enormous challenges to fulfil customers' needs. In order to strengthen the competitiveness of producing companies and to cope with global mega trends like increasing volatility and globalization modern production systems have to be lean and flexible. To put this into practice, the methods of lean manufacturing are most suitable. (Abele \& Reinhart, 2011) In producing companies, which are influenced by the concepts and mindsets of these methods, the strive for operative excellence is a driving factor for continuous improvement, international competitiveness and corporate success.

The concept of lean manufacturing bases on the work of Taiichi Ohno at Toyota (in the 1950s) and was described the first time by Krafcic and Womack in 1988 respectively 1990 (Al-Aomar, 2011; Ohno, 1982; Krafcic, 1988). The main principles are the increase of production flow, the elimination of waste and variability as well as the involvement of employees. (Womack, Jones, \& Roos, 1990) By eliminating waste and reducing lead time, the productivity of companies, work in progress levels and the flexibility regarding volume and variants can be systematically improved (Damm, 2006; Oeltjenbruns, 2000; Rogalski, 2010). So capacities and resources can be used in a more ideal way (Caridi \& Cavalieri, 2004; Doolen \& Hacker, 2005; Lian \& van Landeghem, 2002).

In order to meet the claim of a holistic improvement on the production system-level, the method of value stream mapping was developed as a tool for the implementation of lean thinking. The focus of this method is not on optimizing single (production) processes, rather entire process chains from intake to delivery of goods. (Rother \& Shook, 1999; Bokranz \& Landau, 2006) Value stream mapping is widely accepted in industry and already established as a standard approach especially in the automotive sector (Haemmerle \& Rally, 2010; Brueggemann \& Mueller, 2008).

An optimization project in industrial practice, which is based on the approach of the conventional value stream method, usually begins with the selection of a product family. The analysis of the existing value stream, the derivation of a better future state and the implementation of optimization measures at selected locations are the following steps (Erlach, 2010; Rother \& Shook, 1999). The actual implementation is mostly based on the trial and error principle because the future state is not validated (Marvel \& Standridge, 2009; Standridge \& Marvel, 2006). As of this lacking 
validation / prior quantification of developed target states and the associated absence of hard facts through key performance indicators (KPIs), many managers shy away from lean projects at all (Detty \& Yingling, 2000; Abdulmalek \& Rajgopal, 2007). Moreover, in practice, rarely alternative system designs are derived, but only a single future state pursued (Wolff, 2013). Likewise a value stream map derived out of a volatile production system does not include the variability of internal factors like cycle times, technical availability, setup or idle times as well as variability of external factors like fluctuations in demand. This paper is to show, how the restrictions mentioned here can be solved pursuing an enhanced procedure model for value stream optimization.

\subsection{State of the art value stream optimization}

This chapter gives an overview about existing procedure models for value stream optimization to discuss the necessity for the development of an enhanced approach.

As stated above, the first procedure model for value stream optimization was developed by Rother and Shook (1999). At first it aims to assess the product family with the highest potential, then to analyze and map the real production processes and to derive and implement a more suitable future state. The model is directed on the immediate implementation of one future state and to continuously improve that in small steps (Rother \& Shook, 1999; McDonald, van Aken, \& Rentes, 2002). A future state validation, the development of multiple future states or the inclusion of volatile data are not suggested, see figure 1.

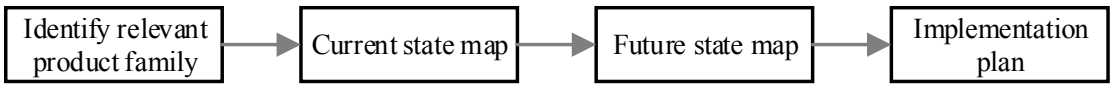

Figure 1. The first value stream optimization approach by Rother and Shook (1999)

Based on Rother and Shook's approach the model developed by Feld (2001) is enhanced mainly by the accompanying element of continuous training of the employees. The identification of a relevant product family is included in the phase of lean assessment as well as the identification of potential areas of opportunity and leverage points. A deeper analysis of these leverages is proposed in the next phase, the current state map, where a qualitative future state design results after considering lean principles. (Feld, 2001) The described changes are not specifically modeled and evaluated before implementation (Marvel \& Standridge, 2009), also multiple designs or variable data are not considered in the analysis or design phase, see figure 2.

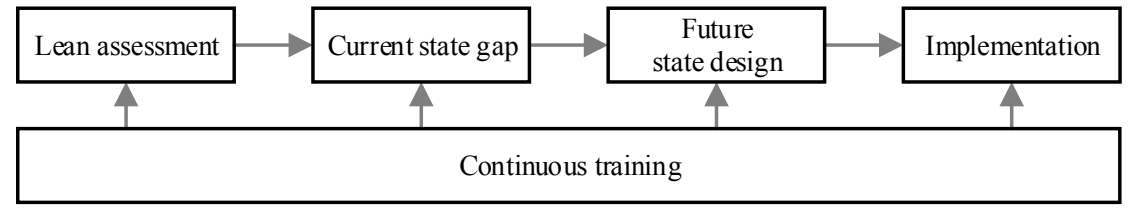

Figure 2. The lean manufacturing road map by Feld (2001)

Hobbs (2004) suggests a circular representation of an operative optimization approach, where the mindset of continuous improvement is underlain. The procedure model has not a project-character as the other approaches but is revolving. A phase for validation or quantification is not included in the model, also it is not shown how the process of factory modeling is actually performed. The handling of variability as well as the development of multiple possible future states is not included, see figure 3.

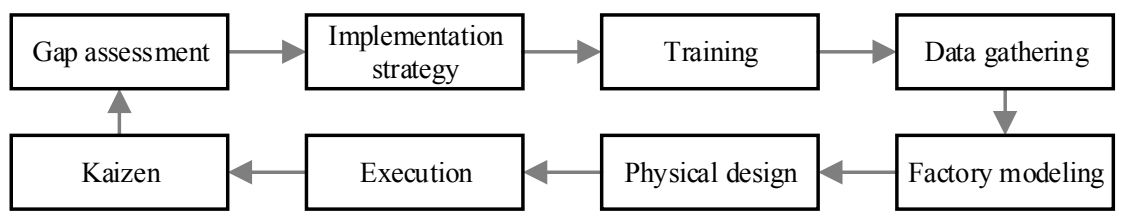

Figure 3. The disciplined approach to lean manufacturing by Hobbs (2004), visualization cf. (Marvel \& Standridge, 2009)

A different procedure model is proposed by Cai and You (2008) for the application especially in design projects for supply chains and the associated project management. It is not an approach for material flow processes, but only for administrative processes. After a value stream analysis a waste elimination process is proposed, which should lead to an optimized value stream. Afterwards this model is transformed into a design structure matrix and an optimized future state will result. The authors are not stating, how the value stream models are visualized in practice, how the data 
structure has to be arranged and give only a very qualitative implementation recommendation. A prior validation of the expected outcome does not take place, but multiple possible system alternatives are considered, see figure 4 .

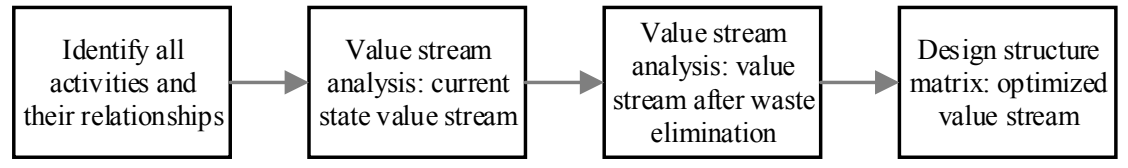

Figure 4. The value stream analysis process by Cai and You (2008)

Marvel and Standridge (2009) developed a simulation-enhanced approach to lean manufacturing in five steps, based on the procedure model by Feld, with the aim of validating the developed future state. The validation step may be performed using discrete event computer simulation and should directly address the effectiveness of the developed future state (Marvel \& Standridge, 2009). Variability is addressed in the validation phase but the development of multiple future states is not discussed, see figure 5 .

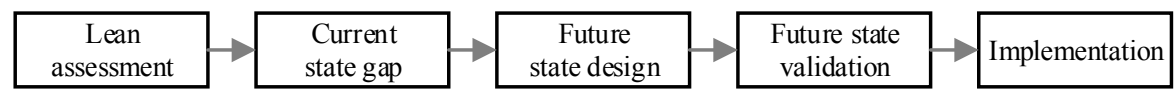

Figure 5. The simulation-enhanced approach to lean manufacturing by Marvel and Standridge (2009)

$\mathrm{Lu}$, Yang and Wang (2011) combine the value stream method with simulation and parameter optimization as well as a subsequent multi-criteria assessment (MCDM: multi-criteria decision making) of the most suitable set of parameters for one developed future state. Variability is addressed within the method as well as the validation of the future state to provide evidence for decision makers. The development of multiple future states is not addressed, see figure 6 .

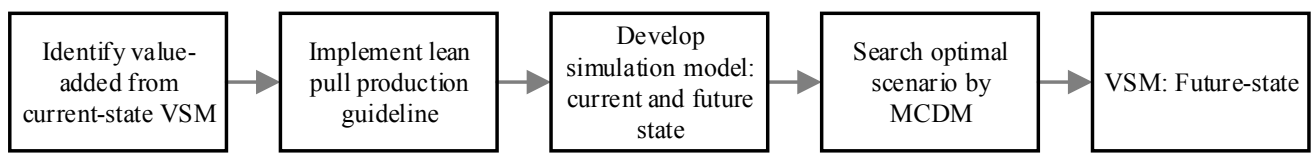

Figure 6. The lean implementation procedure by Lu, Yang and Wang (2011)

Another methodical approach for value stream optimization is suggested by Wolff (2013). It was developed to overcome the limitations of the state of the art method and includes a validation of multiple future states (Wolff, 2013). A comprehensive consideration of variability is only done in the simulation model, not in the analysis, design and the assessment phase, see figure 7 .

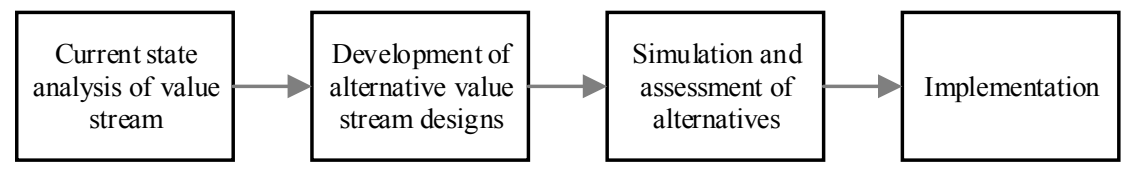

Figure 7. Method for simulation based value stream optimization by Wolff (2013)

\subsection{Necessity for the development of an enhanced approach}

The history shows that quantification modules become more and more important in the implementation practice of the value stream optimization approach. Also the development of multiple future states is suggested more frequently nowadays. The reason therefore lies in the complexity of modern material flows where a high number of variables and design possibilities have to be considered during the development of future states. It is not very likely that the one future state which is developed following one of the above mentioned procedure models really reflects the best option for the examined production system. The aspect of a future state validation or quantification is suggested more frequently in literature, mainly to support decision makers with information about the effectiveness of future states and therefore to foster the adoption of necessary system changes. Following such procedure models, which suggest a future state validation, the use of simulation as a tool is mentioned. Herein variability of process parameters is considered using different mathematical distributions. To use this intrinsic variability in a constructive way it also has to be taken into consideration during the selection process of different future states. The amount of variability has to be made transparent before a qualified decision for choosing a design alternative can be made. This variability which leads to uncertainties in investment decisions is not discussed and made transparent in a manageable way by state of the art methods.

The aspect of, how certain is it, that the selected alternative is really the best, could support decision makers with beneficial additional information. Therefore an enhanced procedure model which helps to consider variability during 
the whole optimization process was developed and is shown in the next paragraph.

\section{Methodology and study design}

When performing a value stream optimization project in practice, regardless of the applied procedure model, there is always the task of modeling the chosen section of the production system in an abstract notation. For this process the tool of value stream analysis was developed, which gives a good level of abstraction and considers both material- as well as information-flow of the production system. The nature of this method is to make a snapshot of the current system state without consideration of dynamic behaviour. The representation of a volatile production system with a static model certainly includes aberrations. These aberrations will get smaller, the more snapshots of the system are contributing to the model. So in the first phase of the proposed procedure model (see figure 8) multiple value stream analyses should be conducted and conclude in one value stream representation of the current state where current variability is considered. Based on this current state model one or multiple value stream designs (future states) are derived and each is described considering possible future variability in the characteristics of parameters. Therefore the value stream notation has been enhanced. After this phase the future state maps have to be quantified and described by KPIs to enable a decision regarding the most suitable future state. Hereby the variability included in the used parameters has to be considered as well using a fuzzy notation. Depending on complexity criteria in this phase either a static or a dynamic quantification has to be conducted. After that a multidimensional decision algorithm provides a ranking of the design alternatives and also shows the amount of variability included in the whole process. Out of a subsequent implementation plan for the most suitable alternative concrete measures are derived and carried out in the physical production system.

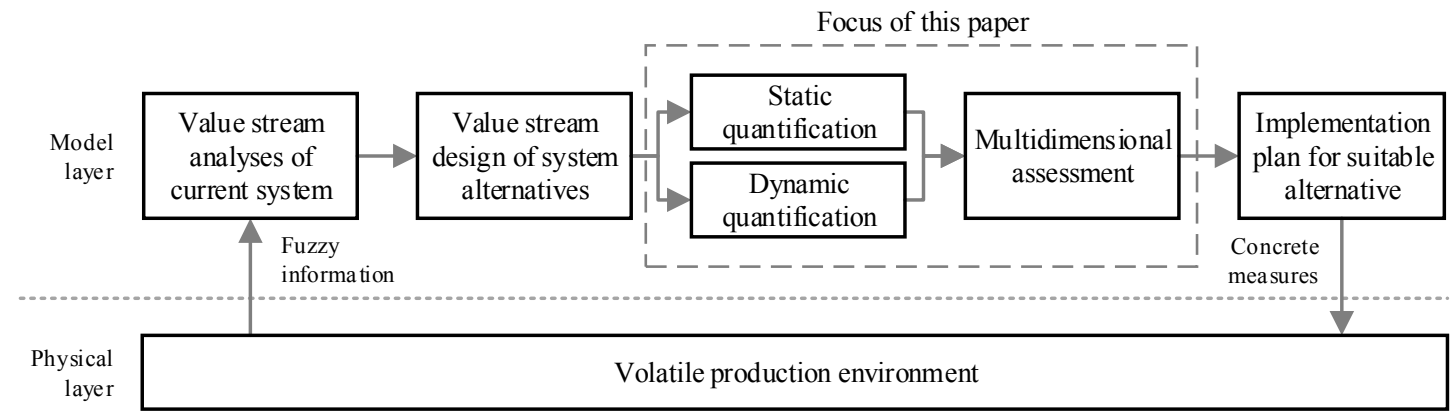

Figure 8. Proposed procedure model for value stream optimization and focus of this paper

The focus of this paper lies in the description of the modules for the static and dynamic quantification explicitly addressing variability. For this purpose the use of fuzzy logic is proposed to model current and possible future variability. Also the phase of multidimensional assessment is explained and discussed intensely. The method as a whole will be applied using a case study in the last paragraph.

\section{Quantification of value stream maps addressing variability}

As already mentioned above there is always the question of how accurate developed future states are fulfilling the required outcome; e. g. if a future state really has a shorter lead time or the inventory level really is lower. In practice the effectiveness of a developed future state can be measured after implementation only, which mostly is linked to a high entrepreneurial risk.

Various authors are addressing that fact by using discrete event simulation to quantify required outcome before implementation (Detty \& Yingling, 2000; Wolff, 2013; Lanza \& Ude, 2010; McDonald, van Aken, \& Rentes, 2002; Standridge \& Marvel, 2006; Abdulmalek \& Rajgopal, 2007; Azadeh, Seifoory, \& Abbasi, 2007; Boerkircher \& Gamber, 2010; Brueggemann \& Mueller, 2008; Lian \& van Landeghem, 2002). Sometimes the efforts for performing such a dynamic quantification (e. g. creating the simulation model) are exceeding the aspired gains. When modeling a dynamic system with a simulation tool, the information content resulting out of a value stream analysis does not suffice in the most cases. Therefore additional data acquisitions from the production system are necessary. (Wolff, 2013) Systems, which are characterized by low variability, low interconnectedness and low combinatorial and dynamic complexity, don't have to be simulated. Issues in such systems mostly could be solved using analytical methods. Further information about when simulation is not appropriate, cf. (Banks \& Gibson, 1997; Robinson, 2004).

Regardless if a static or dynamic quantification is performed after a value stream design process, the variability included in these designs has to be made transparent and usable for a decision making process. This chapter shows how such a process of quantification can be performed and how data has to be treated in order to allow a subsequent 
decision making including variability. Therefore the next paragraph gives a brief introduction into fuzzy logic, which is necessary to understand the subsequent data transformations.

\subsection{Fuzzy Logic}

To handle variability of value stream parameters in a computational way a mathematical arithmetic framework is required. As one possible methodology for the mathematical handling of variability and uncertainty, fuzzy logic has been developed, based on the theory of fuzzy sets according to Zadeh. (Azadeh, Seifoory, \& Abbasi, 2007; Zadeh, 1965; Bellman \& Zadeh, 1970)

Zadeh defines a fuzzy set as a class of objects, having a range of degrees of membership. This set is characterized by a membership function $\mu(\mathrm{x})$ which assigns each object class a membership degree between zero and one. That means that an object or element is not only located inside or outside the set, but also that this may be "a little" included in the set. The membership to this set is gradually staged and is not related to a probability distribution. (Zadeh, 1965; Zimmermann \& Gutsche, 1991) A possible representation of a fuzzy number and the membership function is shown in figure 9.

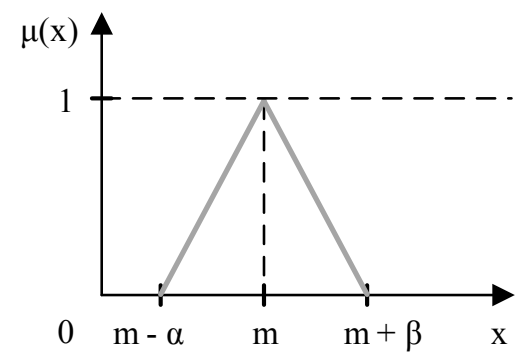

Figure 9. Visualization of a triangular fuzzy number

The formal notation for fuzzy numbers is displayed with a tilde over the literal (Chen, Hwang, \& Hwang, 1992; Geldermann, Sprengler, \& Rentz, 2000; Goumas \& Lygerou, 2000). In this context the membership function of a fuzzy number (e. g. $\tilde{M}$ ) can be described using a middle value $(\mathrm{m})$, a lower spread $(\alpha)$ and an upper spread $(\beta)$, see equation 1.

Notation of a triangular fuzzy number

$$
\tilde{M}=(m ; \alpha ; \beta)
$$

Elementary fuzzy algebra is required when working with fuzzy numbers. The operations used in the further algorithms are fuzzy addition $(\oplus)$, fuzzy subtraction $(\ominus$ ), fuzzy multiplication $(\odot)$ and fuzzy division $(\oslash)$ (Chen, Hwang, \& Hwang, 1992; Geldermann, Sprengler, \& Rentz, 2000).

The further modeling will be performed using triangular fuzzy numbers. More complex membership functions cause greater computational complexity without adding significant benefits (Braglia \& Zammori, 2009; Driankov, Hellendorn, \& Reinfrank, 1993). Triangular fuzzy numbers are also easy to utilize and give a relatively good representation of the situations under observance.

Further fuzzy numbers will be used to describe variable value stream indicators like inventory, cycle times, and flexibility or lead times. The use of stochastically variables is not considered in this context because no probabilities can be derived out of the value stream analyses and their snapshot character.

\subsection{Static quantification addressing variability}

In this paragraph it is shown how to quantify developed future state maps and explicitly consider variability in a static way. As mentioned before in the approach suggested in figure 8, multiple value stream analyses are being conducted in order to get a better picture of the underlying process characteristics. Hereby slightly different process parameters (changeover times, cycle times or availabilities) and inventory levels are identified during these analyses. To model these multiple value stream analyses in a single one, the use of fuzzy logic is proposed here. Out of for example three recordings of a changeover time one fuzzy number can be derived easily, see equations $2-3$ in section 3.4. Doing that with all parameters of all (e. g. three) analyses one current state map will conclude using following enhanced value stream notation for processes and inventory, see figure 10. Availabilities and performance inhibitions can be assessed in the same way according to Roessler and Abele (2013). 

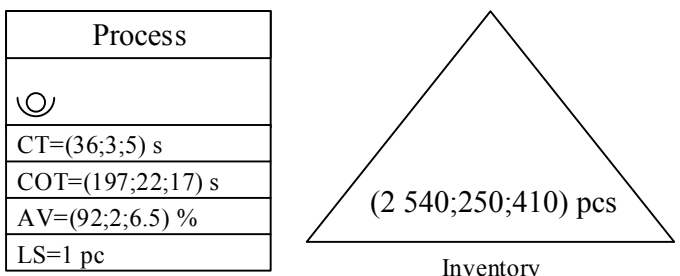

CT: cycle time
COT: changeover time
AV: availability
LS: lot size
pc(s): piece(s)
s: seconds

Figure 10. Enhanced value stream notation for processes and inventory

using fuzzy variables to describe variability without the knowledge about probabilities

A similar approach is proposed by Braglia and Zammori (2009) and Seyedhosseini et al. (2013), namely the recording of expert guesses during one value stream analysis instead of performing multiple analyses. Hereby the process owners are asked for a pessimistic, an optimistic and a realistic process time to calculate one fuzzy number out of this. However experts usually cannot estimate stock. Another restriction is that the process owners can only provide information about their process, detailed information about e. g. automatic processes can't be recorded that way. Also expert guesses could underlie a vast uncertainty. Both authors are using one KPI in order to compare multiple value stream maps, the total productive lead time. Another possible way of addressing the issue of data collection is the inclusion of live information out of data acquisition systems.

Out of the one emerging current state map multiple future state maps can be derived following some design principles (Rother \& Shook, 1999; Erlach, 2010). These future state maps also have to be described using fuzzy numbers, where more qualified guess is needed in order to describe future variation, e. g. future cycle and changeover times. The fuzzy stock levels for supermarkets or FIFO lanes which are designed in future states can be modeled easily by taking the minimum and maximum plan value and also calculate the fuzzy stock according to equations 2-3.

After the current and the multiple future states are modeled using fuzzy numbers they can be quantified in a multidimensional way using different value stream KPIs. Here it is suggested to use the overall inventory level [pcs], the lead time at bottleneck chain [h], the value added time share (VATS) [\%], the on-time in-full potential (OTIF) [\%] and the volume flexibility [\%] to describe value stream maps. For further possible KPIs see Evans and Alexander (Evans \& Alexander, 2007).

The first indicator, the overall inventory level [pcs] can be easily calculated by a fuzzy addition of all inventory of the value stream. This could be enriched by the fixed capital for each material type, but in this respect only the absolute numbers are considered. The second indicator, the lead time at bottle neck chain [h] calculates out of the sum of all cycle times for the bottleneck value chain and all inventory levels multiplied with the customer's tact. The customer's tact indicates the time interval, in which the customer requests exactly one end product. The VATS indicator is calculated by dividing the total value added time (sum of all cycle times at bottleneck chain processes) by the lead time at bottleneck chain. The OTIF potential is calculated by a fuzzy division of the customer's tact by the effective cycle time (cycle time without breakdowns) of the bottleneck process. This potential can be bigger than 1; that means that the bottleneck process has the potential of producing more parts in the same time. If this indicator is below 1, the customer's demand cannot be fulfilled in the right amount. The volume flexibility is calculated by subtracting 1 by the OTIF potential.

Following these calculation rules a set of multiple fuzzy criteria for each future state alternative results. These sets can be used in a subsequent decision making process which is shown in paragraph 4 .

\subsection{Dynamic quantification addressing variability}

A dynamic quantification of developed future states, namely simulation, is done when either the combinatorial or the dynamical complexity of the system is too high (Robinson, 2004). The calculation of inventory levels, lead times, throughput or other KPIs using arithmetic methods thus is not possible. Especially the variation of inventory levels for different scenarios cannot be observed by only a future state map as a static model (McDonald, van Aken, \& Rentes, 2002). As stated above the use of simulation to quantify future states is suggested by various authors.

Simulation models in this context are forecast models for (dynamic and combinatorial complex) systems, in which cause and effect relationships cannot be modeled analytically and underlie stochastic influences (Domschke \& Scholl, 2005). In the area of production and logistics systems are mostly modeled by discrete event simulation (Cochran \& Chen, 2005; Daniluk \& Chisu, 2010; Maerz, Krug, Rose, \& Weigert, 2011; Al-Aomar, 2011). In these applications the dynamic and stochastic behavior of systems is characterized by time variant state variables (Domschke \& Scholl, 
2005). Because the use of simulation in the context of value stream mapping is used regularly, the actual simulation process won't be discussed further in this paper.

Including the lack of confidence in input information for simulation models, some difficulties have limited the use of discrete event simulation as a practical tool for some real-world systems (Fente, Knutson, \& Schexnayder, 1999). Generally, modeling activity duration is achieved through importing observed data or probability distributions derived from sample data. However, the use of real data to achieve a good simulation model is time-consuming taken to collect large amounts of field data for reproduction of the real operation system (Law \& Kelton, 2006), cf. (Azadeh, Seifoory, $\&$ Abbasi, 2007). As stated above the process for sufficing data collection exceeds the information content of a classical value stream analysis, so it has to be thoroughly reviewed if simulation is the right quantification method viewing at the expected benefits.

As can be seen here, the inclusion of stochastic variables (equipment availability owing to break downs and scheduled maintenance, variations in customer demand, quality deficiencies etc.) is pretty common and due to modeling imprecisions results of simulation models contain uncertainty due to their output KPIs. In simulation practice a series of different scenarios (for example representing different future states or different parameter settings) are modeled, simulated and compared. Each scenario has to be simulated over a distinct minimum time period in order to achieve a settled condition. Huge amounts of data are resulting for each different scenario which could underlie vast fluctuations. In order to use these measures in decision making about which alternative design suits best, the resulting data sets have to be analyzed and transformed to fuzzy variables.

\subsection{Transformation of data sets to fuzzy numbers}

To make it possible to derive a decision about the most suitable future state, the fuzzy set theory is initially applied to condition resulting data sets. This is done to transform the vectors of e. g. simulation results to manageable input data for the subsequent decision making algorithm. So for each output KPI $C=\left\{c_{1}, c_{2}, \ldots, c_{j}\right\}$ of each future state $\mathrm{A}=\left\{\mathrm{a}_{1}, \mathrm{a}_{2}, \ldots, \mathrm{a}_{\mathrm{i}}\right\}$ one fuzzy number has to be modeled out of the resulting set of $\mathrm{n}$ unique data sets $\left(\mathrm{X}_{\mathrm{ks}}=\mathrm{c}_{\mathrm{k}}\left(\mathrm{a}_{\mathrm{s}}\right)\right)_{\mathrm{n}}$. To describe every column of simulation results with a fuzzy number the values of $\mathrm{m}, \alpha$ and $\beta$ have to be derived, therefore see equations 2-3.

When representing data by the triangular form as middle value $(\mathrm{m})$ the median (also $50 \%$-quantile or $\mathrm{Q}_{0.5}$-value) out of the set of $\mathrm{n}$ results is being considered as the best way of approximation because it divides the set into two areas of numbers, one containing bigger and one containing smaller numbers than the median. Also the median is best used in describing accumulations in sets (Cramér, 1946). The lower and the upper spread are calculated by inclusion of the $5 \%$ and $95 \%$ quantiles to minimize the impact of outlier to the absolute spread of the resulting fuzzy number.

$$
\begin{aligned}
& \mathrm{m} \text { for all } \mathrm{n} \\
& m=Q_{0.5}\left\{X_{k s_{0}}, \ldots, X_{k s_{n}}\right\} \\
& \alpha=m-Q_{0.05}\left\{X_{k s_{0}}, \ldots, X_{k s_{n}}\right\} \\
& \alpha \text { and } \beta \\
& \beta=Q_{0.95}\left\{X_{k s_{0}}, \ldots, X_{k s_{n}}\right\}-m
\end{aligned}
$$

\section{Multidimensional fuzzy assessment of value stream mapping alternatives}

If all KPIs for all future states are described in fuzzy numbers, a fuzzy decision making process is needed to help providing a ranking of the most suitable value stream alternative. Because there is a discrete number of future states to be considered, this approach has to be out of the field of multi-criteria decision making methods (Hwang \& Yoon, 1981). In this field a series of methods are considered being suitable (e. g. AHP, MAUT, PROMETHEE, TOPSIS, cost utility analysis) to derive multidimensional decisions (Belton \& Stewart, 2002; Hwang \& Yoon, 1981). As an additional requirement to a possible decision method the handling of variability, especially through the use of fuzzy set theory is necessary.

One method which is suitable for considering variability and fuzziness in an evaluation and especially supporting transparency and simplicity for the decision maker is the method of Fuzzy PROMETHEE (F-PROMETHEE) developed by Geldermann, Sprengler and Rentz (2000) based on the original PROMETHEE decision method (Preference ranking organization method for enrichment evaluations) by Brans, Mareschal and Vincke (1984).

This method is introduced next. The first step of the F-PROMETHEE approach is the modeling of the preferences. This is done by including a so called preference function $\left(\mathrm{p}_{\mathrm{k}}\right)$ for each KPI, which assigns every difference value (d) a preference between 0 and 1, see formula 4 (Geldermann, Sprengler, \& Rentz, 2000). 
Fuzzy preference

$$
\begin{gathered}
\tilde{p}_{k}(\tilde{d})=\tilde{p}_{k}\left(c_{k}\left(a_{s}\right) \ominus\right. \\
\left.c_{k}\left(a_{s^{\prime}}\right)\right)=p_{k}(m) ; p_{k}(m)-p_{k}(m-\alpha) ; p_{k}(m+\beta)-p_{k}(m)
\end{gathered}
$$

Brans et al. (1984) suggest six types of functions, which can be used for modeling such preferences. In this paper the Gaussian preference function is used, where the point of inflexion can be calculated using the approach of Queiruga, Walther, Gonzales-Benito and Sprengler (2008). According to the algorithm of F-PROMETHEE in the next step the outcoming preferences have to be weighted with the weights for each KPI and cumulated over all KPIs, see formula 5 (Geldermann, Sprengler, \& Rentz, 2000). Information about the weights of KPIs $\left(\mathrm{w}_{\mathrm{k}}\right)$ are derived through expert interviews with the responsible person for the production system under observance.

$$
\text { Fuzzy outranking relation } \quad \tilde{\pi}\left(a_{s}, a_{s^{\prime}}\right)=\sum_{k=0}^{j} \tilde{w}_{k} \odot \tilde{p}_{k}(\tilde{d})
$$

As the last step of the evaluation process the outranking relations have to be cumulated over all KPIs to derive the strengths $\left(\tilde{\Phi}^{+}\right)$and weaknesses $\left(\tilde{\Phi}^{-}\right)$of the design alternatives. The sum of these positive and negative flows result in the net flows $\left(\tilde{\Phi}^{\text {net }}\right)$, the values for the fuzzy ranking of the alternatives (Brans, Mareschal, \& Vincke, 1984; Geldermann, Sprengler, \& Rentz, 2000).

\section{Case study}

For testing and validating the enhanced value stream optimization approach in industrial practice, a case study was conducted at the Center for Industrial Productivity at the Technical University Darmstadt, a real production environment for educational purposes, cf. (Abele, Eichhorn, \& Kuhn, 2007).

The production system produces pneumatic cylinders for various industrial applications in four variants. The company delivers two times per day to the customer and produces in three shifts per day, each lasting 48 minutes without breaks. The customer's tact is 60 seconds and the demand per shift is 48 parts. The bucket size is four, in the future states this corresponds to one Kanban card. Figure 11 summarizes the three conducted value stream analyses in one visualization, following the guidelines of figure 10 and using fuzzy representations according to equations 2-3.

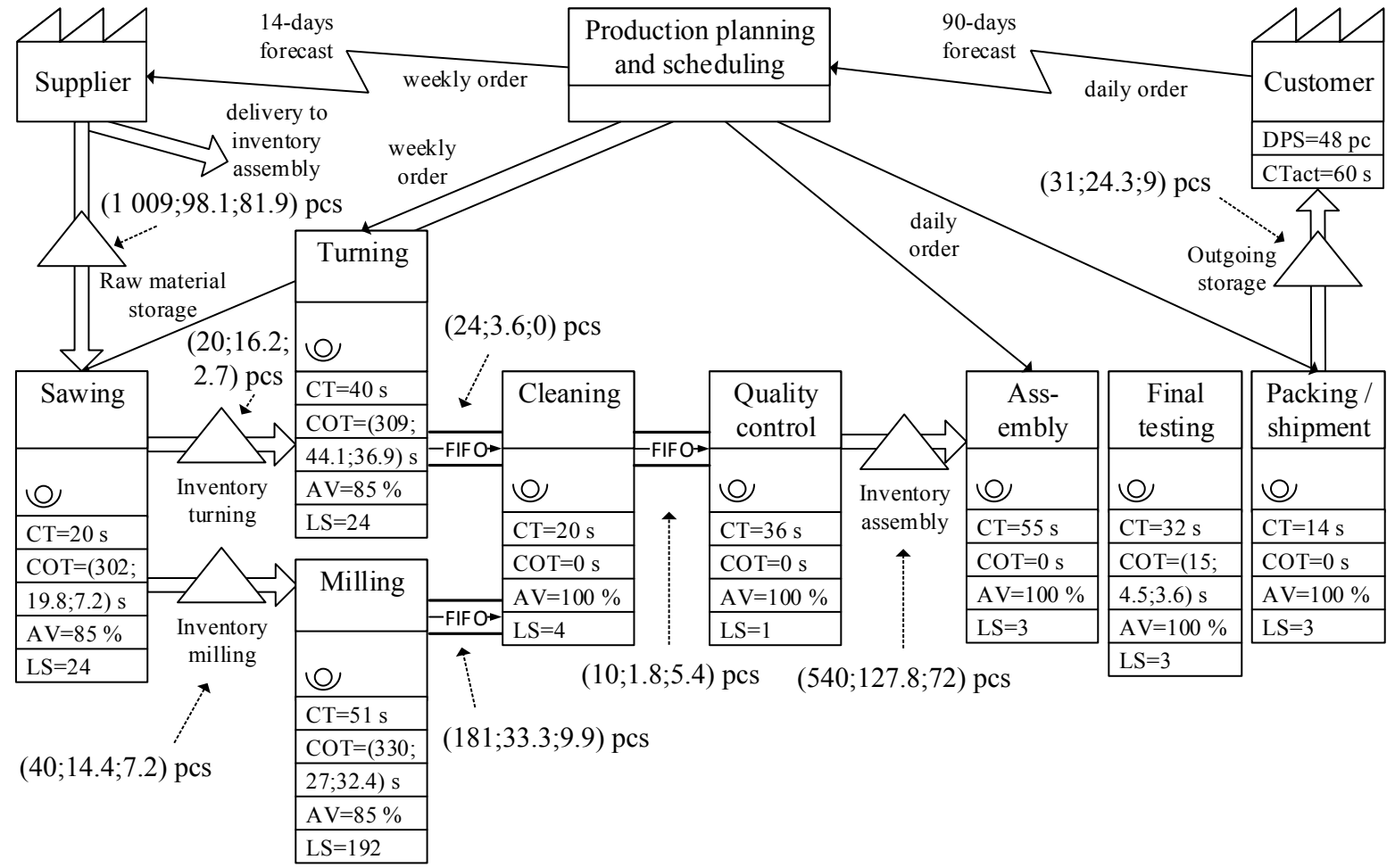

Figure 11. Current state map of the production system (CS)

Detailed information about the results of the three value stream analyses are shown in table 1 and table 2, also how they are transformed into fuzzy numbers. 
Table 1. Stock counts at inventories in the current state

\begin{tabular}{lllll}
\hline Inventory & $\begin{array}{l}\text { Stock at } \\
\text { count } 1\end{array}$ & $\begin{array}{l}\text { Stock at } \\
\text { count } 2\end{array}$ & $\begin{array}{l}\text { Stock at } \\
\text { count } 3\end{array}$ & $\begin{array}{l}\text { Fuzzy stock } \\
(\mathrm{m} ; \alpha ; \beta)[\mathrm{pcs}]\end{array}$ \\
\hline Raw material storage & $1100 \mathrm{pcs}$ & $900 \mathrm{pcs}$ & $1009 \mathrm{pcs}$ & $1009 ; 98.1 ; 81.9$ \\
Inventory turning & $20 \mathrm{pcs}$ & $23 \mathrm{pcs}$ & $2 \mathrm{pcs}$ & $20 ; 16.2 ; 2.7$ \\
Inventory milling & $40 \mathrm{pcs}$ & $48 \mathrm{pcs}$ & $24 \mathrm{pcs}$ & $40 ; 14.4 ; 7.2$ \\
FIFO turning & $24 \mathrm{pcs}$ & $20 \mathrm{pcs}$ & $24 \mathrm{pcs}$ & $24 ; 3.6 ; 0$ \\
FIFO milling & $192 \mathrm{pcs}$ & $181 \mathrm{pcs}$ & $144 \mathrm{pcs}$ & $181 ; 33.3 ; 9.9$ \\
FIFO cleaning & $16 \mathrm{pcs}$ & $8 \mathrm{pcs}$ & $10 \mathrm{pcs}$ & $10 ; 1.8 ; 5.4$ \\
Inventory assembly & $398 \mathrm{pcs}$ & $540 \mathrm{pcs}$ & $620 \mathrm{pcs}$ & $540 ; 127.8 ; 72$ \\
Outgoing storage & $41 \mathrm{pcs}$ & $31 \mathrm{pcs}$ & $4 \mathrm{pcs}$ & $31 ; 24.3 ; 9$ \\
\hline
\end{tabular}

Table 2. Changeover times at processes in the current state

\begin{tabular}{lllll}
\hline Process & $\begin{array}{l}\text { COT at } \\
\text { count } 1\end{array}$ & $\begin{array}{l}\text { COT at } \\
\text { count } 2\end{array}$ & $\begin{array}{l}\text { COT at } \\
\text { count } 3\end{array}$ & $\begin{array}{l}\text { Fuzzy COT } \\
(\mathrm{m} ; \alpha ; \beta)[\mathrm{s}]\end{array}$ \\
\hline Sawing & $280 \mathrm{~s}$ & $302 \mathrm{~s}$ & $310 \mathrm{~s}$ & $302 ; 19.8 ; 7.2$ \\
Turning & $350 \mathrm{~s}$ & $260 \mathrm{~s}$ & $309 \mathrm{~s}$ & $309 ; 44.1 ; 36.9$ \\
Milling & $366 \mathrm{~s}$ & $300 \mathrm{~s}$ & $330 \mathrm{~s}$ & $330 ; 27 ; 32.4$ \\
Final testing & $10 \mathrm{~s}$ & $19 \mathrm{~s}$ & $15 \mathrm{~s}$ & $15 ; 4.5 ; 3.6$ \\
\hline
\end{tabular}

The next step of the proposed method prescribes the development of multiple future states following the existing design guidelines, cf. (Rother \& Shook, 1999; Erlach, 2010). This step was performed with a team of four people with expert knowledge in value stream mapping. Figure 12 and figure 13 show these developed future states.

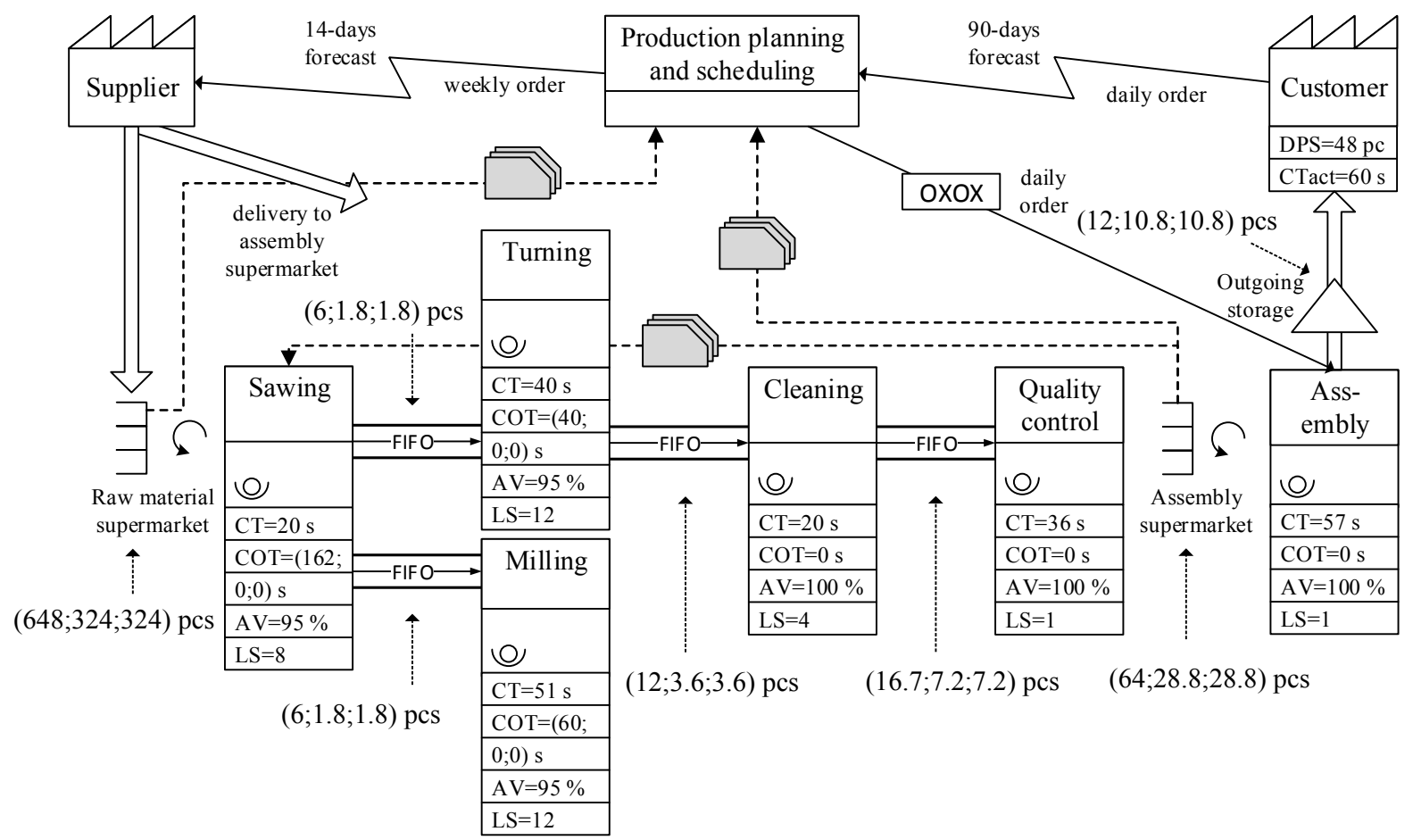

Figure 12. Future state map 1 of the production system (FS1) 


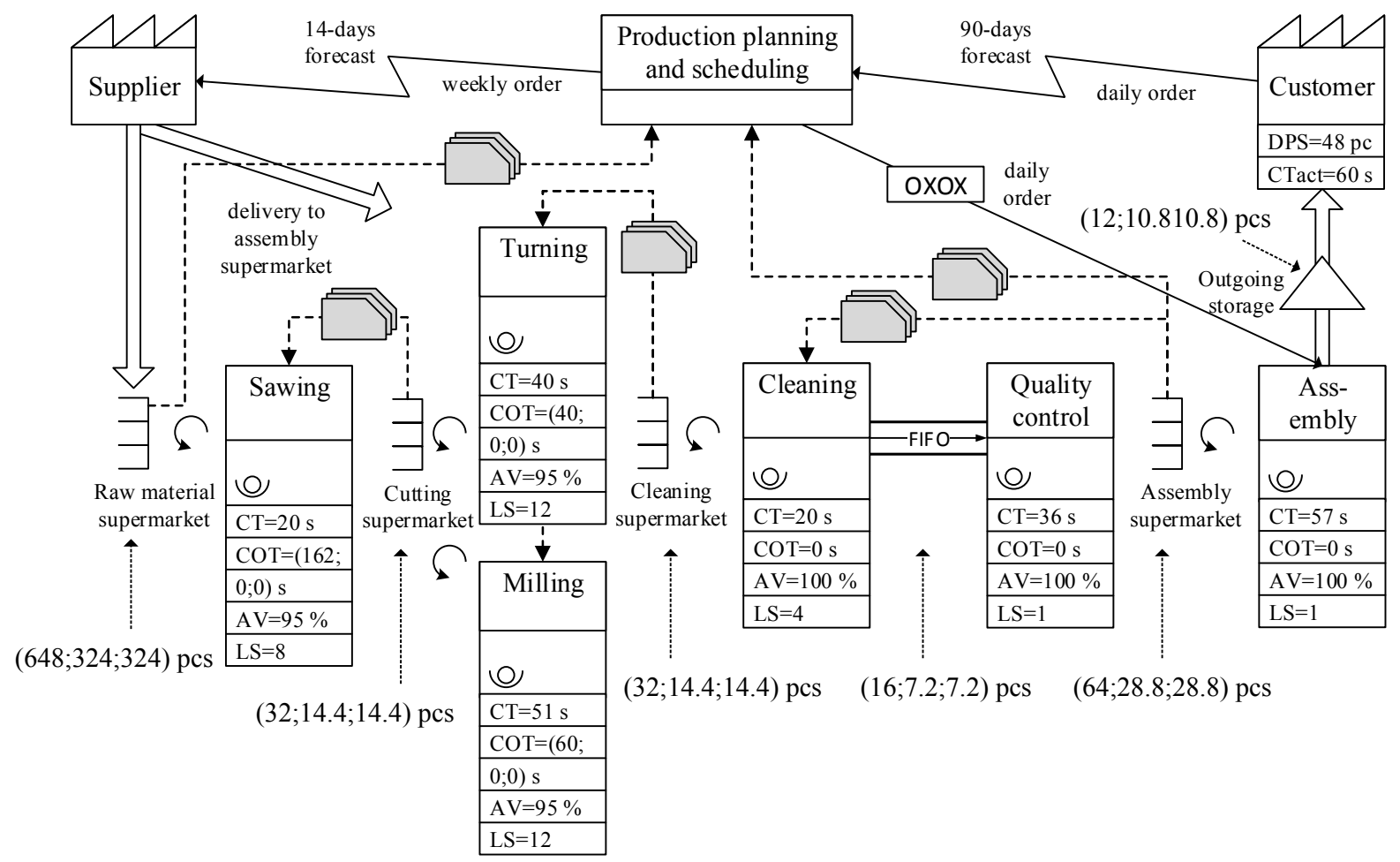

Figure 13. Future state map 2 of the production system (FS2)

Detailed information about the approximations of the two future state designs are shown in table 3-5, also how they are transformed into fuzzy numbers.

Table 3. Defined stocks at inventories in future state 1

\begin{tabular}{llll}
\hline Inventory & $\begin{array}{l}\text { Stock at defined } \\
\text { minimum }\end{array}$ & $\begin{array}{l}\text { Stock at physical } \\
\text { maximum }\end{array}$ & $\begin{array}{l}\text { Fuzzy stock } \\
(\mathrm{m} ; \alpha ; \beta)[\mathrm{pcs}]\end{array}$ \\
\hline Raw material supermarket & $288 \mathrm{pcs}$ & $1008 \mathrm{pcs}$ & $648 ; 324 ; 324$ \\
FIFO sawing-turning & $4 \mathrm{pcs}$ & $8 \mathrm{pcs}$ & $6 ; 1.8 ; 1.8$ \\
FIFO sawing- milling & $4 \mathrm{pcs}$ & $8 \mathrm{pcs}$ & $6 ; 1.8 ; 1.8$ \\
FIFO before cleaning & $8 \mathrm{pcs}$ & $16 \mathrm{pcs}$ & $12 ; 3.6 ; 3.6$ \\
FIFO before quality control & $8 \mathrm{pcs}$ & $24 \mathrm{pcs}$ & $16 ; 7.2 ; 7.2$ \\
Assembly supermarket & $32 \mathrm{pcs}$ & $96 \mathrm{pcs}$ & $64 ; 28.8 ; 28.8$ \\
Outgoing storage & $0 \mathrm{pcs}$ & $24 \mathrm{pcs}$ & $12 ; 10.8 ; 10.8$ \\
\hline
\end{tabular}

Table 4. Defined stocks at inventories in future state 2

\begin{tabular}{llll}
\hline Inventory & $\begin{array}{l}\text { Stock at defined } \\
\text { minimum }\end{array}$ & $\begin{array}{l}\text { Stock at physical } \\
\text { maximum }\end{array}$ & $\begin{array}{l}\text { Fuzzy stock } \\
(\mathrm{m} ; \alpha ; \beta)[\mathrm{pcs}]\end{array}$ \\
\hline Raw material supermarket & $288 \mathrm{pcs}$ & $1008 \mathrm{pcs}$ & $648 ; 324 ; 324$ \\
Cutting supermarket & $16 \mathrm{pcs}$ & $48 \mathrm{pcs}$ & $32 ; 14.4 ; 14.4$ \\
Cleaning supermarket & $16 \mathrm{pcs}$ & $48 \mathrm{pcs}$ & $32 ; 14.4 ; 14.4$ \\
FIFO before quality control & $8 \mathrm{pcs}$ & $24 \mathrm{pcs}$ & $16 ; 7.2 ; 7.2$ \\
Assembly supermarket & $32 \mathrm{pcs}$ & $96 \mathrm{pcs}$ & $64 ; 28.8 ; 28.8$ \\
Outgoing storage & $0 \mathrm{pcs}$ & $24 \mathrm{pcs}$ & $12 ; 10.8 ; 10.8$ \\
\hline
\end{tabular}


Table 5. Estimated changeover times at future processes

\begin{tabular}{ll}
\hline Process & $\begin{array}{l}\text { Fuzzy COT } \\
(\mathrm{m} ; \alpha ; \beta)[\mathrm{s}]\end{array}$ \\
\hline Sawing & $162 ; 0 ; 0$ \\
Turning & $40 ; 0 ; 0$ \\
Milling & $60 ; 0 ; 0$ \\
Final testing & $0 ; 0 ; 0$ \\
\hline
\end{tabular}

\subsection{Static quantification and data transformation}

This paragraph gives an overview of the results of the static quantification according to the defined KPIs and calculation rules out of paragraph 3.2. The data transformation was also performed according to equations 2-3. Tables 6-8 contain the derived KPIs during the static quantification for both future states as well as the current state, which was also modeled for comparison.

Table 6. Results of the static quantification of the current state value stream

\begin{tabular}{ll}
\hline KPI & $\begin{array}{l}\text { Fuzzy number } \\
(\mathrm{m} ; \alpha ; \beta)\end{array}$ \\
\hline Inventory [pcs] & $1855 ; 319.5 ; 188.1$ \\
Lead time bottleneck chain $[\mathrm{h}]$ & $30.98 ; 5.33 ; 3.14$ \\
Value added time share [\%] & $0.2 ; 0.02 ; 0.04$ \\
On-time in-full potential [\%] & $73 ; 3 ; 2$ \\
Volume flexibility [\%] & $0 ; 0 ; 0$ \\
\hline
\end{tabular}

Table 7. Results of the static quantification of the future state 1 value stream

\begin{tabular}{ll}
\hline KPI & $\begin{array}{l}\text { Fuzzy number } \\
(\mathrm{m} ; \alpha ; \beta)\end{array}$ \\
\hline Inventory [pcs] & $764 ; 378 ; 378$ \\
Lead time bottle neck chain $[\mathrm{h}]$ & $12.78 ; 6.3 ; 6.3$ \\
Value added time share [\%] & $0.4 ; 0.13 ; 0.39$ \\
On-time in-full potential [\%] & $105 ; 0 ; 0$ \\
Volume flexibility [\%] & $5 ; 0 ; 0$ \\
\hline
\end{tabular}

Table 8. Results of the static quantification of the future state 2 value stream

\begin{tabular}{ll}
\hline KPI & $\begin{array}{l}\text { Fuzzy number } \\
(\mathrm{m} ; \alpha ; \beta)\end{array}$ \\
\hline Inventory [pcs] & $804 ; 399.6 ; 399.6$ \\
Lead time bottle neck chain [h] & $13.45 ; 6.66 ; 6.66$ \\
Value added time share [\%] & $0.38 ; 0.13 ; 0.37$ \\
On-time in-full potential [\%] & $105 ; 0 ; 0$ \\
Volume flexibility [\%] & $5 ; 0 ; 0$ \\
\hline
\end{tabular}

\subsection{Dynamic quantification and data transformation}

The data used for simulating material flow systems typically underlies uncertainty. Uncertainty can be caused either by changing external conditions during the simulation period, e. g. whether a forecast for the customer demand indeed will be maintained. On the contrary by internal parameters of the simulated system itself, e. g. whether the assumed set up or process time will be achieved in practice. For those cases it is recommended to simulate multiple scenarios within 
one simulated value stream state leading to a sensitivity analysis. Hence multiple simulation experiments are executed for each value stream state with a vector for uncertain parameters, here e. g. for the current state consisting of a minimum and a maximum value out of the fuzzy values out of the analysis. The number of simulation experiments (o) depends on the number of assumed values for each input parameter $(v)$ and the general number of uncertain input parameters $(\mathrm{u})$. See therefore equation 6.

Number of simulation experiments

$$
o=v^{u}
$$

For the purpose of developing the simulation model, additional information has to be identified out of the production system like personal resources, physical transport devices, transport ways, work plans, bills of material as well as orders, quantities and due dates, cf. (Wolff, 2013). Stochastical information was used to model the ordered variants, delivery dates and scrap.

After modeling the current state value stream based on the merged value stream analyses and a second data collection process multiple simulation experiments are necessary. Here 16 simulation experiments (each simulating a period of 1 000 parts) are necessary as four uncertain parameters $(\mathrm{u}=4)$ are considered, each with a minimum and a maximum value $(\mathrm{v}=2)$, considering the defined quantiles. The following four uncertain input parameters were taken into account in order to identify the underlying sensitivities of the current system, values result out of table 2:

- Changeover time sawing: $\min .282 .2 \mathrm{~s}$, max. $309.2 \mathrm{~s}$

- Changeover time turning: min. $264.9 \mathrm{~s}, \max .345 .9 \mathrm{~s}$

- Changeover time milling: min. $303 \mathrm{~s}$, max. $362.4 \mathrm{~s}$

- Changeover time final testing: $\min .10 .5 \mathrm{~s}$, max. $18.6 \mathrm{~s}$

Chosen simulation results for the current state are exemplarily visualized in table 9. The models were created and simulated using the software Tecnomatix Plant Simulation 10.1 by Siemens.

Table 9. Set of the first ten simulation results for the current state regarding KPI inventory (each value is a middle value out of 1000 simulated parts).

\begin{tabular}{ll}
\hline $\begin{array}{l}\text { Simulation } \\
\text { experiment [\#] }\end{array}$ & $\begin{array}{l}\text { Current state average } \\
\text { inventory [pcs] }\end{array}$ \\
\hline 1 & 621 \\
2 & 1370 \\
3 & 897 \\
4 & 1160 \\
5 & 1211 \\
6 & 1248 \\
7 & 1174 \\
8 & 951 \\
9 & 1004 \\
10 & 941 \\
\hline
\end{tabular}

For both future states no multiple experiments were conducted as any information about uncertain changeover times are given. During the simulation only the above mentioned stochastically influence parameters were modeled. Also in the future state models each 1000 parts were simulated and resulting data sets were analyzed using equations 2 and 3 for fuzzy representation. Tables 10-12 contain the derived KPIs during the dynamic quantification for the current state as well as both future states. 
Table 10. Results of the dynamic quantification of the current state value stream

\begin{tabular}{ll}
\hline KPI & $\begin{array}{l}\text { Fuzzy number } \\
(\mathrm{m} ; \mathrm{\alpha} ; \beta)\end{array}$ \\
\hline Inventory [pcs] & $1082 ; 336.8 ; 233.1$ \\
Lead time bottle neck chain [h] & $42.12 ; 8.32 ; 15.9$ \\
Value added time share [\%] & $0.18 ; 0.03 ; 0.12$ \\
On-time in-full potential [\%] & $61 ; 3 ; 12.5$ \\
Volume flexibility [\%] & $0 ; 0 ; 0$ \\
\hline
\end{tabular}

Table 11. Results of the dynamic quantification of the future state 1 value stream

\begin{tabular}{ll}
\hline KPI & $\begin{array}{l}\text { Fuzzy number } \\
(\mathrm{m} ; \alpha ; \beta)\end{array}$ \\
\hline Inventory [pcs] & $951.5 ; 310.9 ; 52.70$ \\
Lead time bottle neck chain [h] & $21 ; 4 ; 11.8$ \\
Value added time share [\%] & $0.85 ; 0.1 ; 0.08$ \\
On-time in-full potential [\%] & $94.8 ; 5.12 ; 2$ \\
Volume flexibility [\%] & $0 ; 0 ; 1$ \\
\hline
\end{tabular}

Table 12. Results of the dynamic quantification of the future state 2 value stream

\begin{tabular}{ll}
\hline KPI & $\begin{array}{l}\text { Fuzzy number } \\
(\mathrm{m} ; \alpha ; \beta)\end{array}$ \\
\hline Inventory [pcs] & $1009 ; 326.85 ; 156.8$ \\
Lead time bottle neck chain [h] & $31.95 ; 7.06 ; 8.21$ \\
Value added time share [\%] & $0.6 ; 0.02 ; 0.09$ \\
On-time in-full potential [\%] & $93.69 ; 4.59 ; 1.88$ \\
Volume flexibility [\%] & $0 ; 0 ; 0$ \\
\hline
\end{tabular}

\subsection{Multidimensional fuzzy assessment}

After deriving all KPIs for each value stream alternative and modeling them using fuzzy numbers, the subsequent decision making approach based on F-PROMETHEE can be conducted. Here two multidimensional assessments were performed, one for the statically and one for the dynamical quantification in order to compare the results. Tables 13 and 14 summarize the input data for the F-PROMETHEE algorithm. The criterion $\mathrm{e}_{\mathrm{k}}$ indicates the direction of the KPI.

Table 13. Static derived input data for decision algorithm

\begin{tabular}{lllllll}
\hline $\mathrm{c}_{\mathrm{k}}$ & $\mathrm{e}_{\mathrm{k}}$ & $\mathrm{w}_{\mathrm{k}}$ & $\sigma_{\mathrm{k}}$ & $\mathrm{a}_{0}(\mathrm{CS})$ & $\mathrm{a}_{1}(\mathrm{FS} 1)$ & $\mathrm{a}_{2}(\mathrm{FS} 2)$ \\
\hline $\mathrm{INV}$ & $\min$ & 3 & 390.33 & $1855 ; 319.5 ; 188.1$ & $764 ; 378 ; 378$ & $804 ; 399.6 ; 399.6$ \\
LTB & $\min$ & 4 & 6.51 & $30.98 ; 5.325 ; 3.135$ & $12.78 ; 6.3 ; 6.3$ & $13.45 ; 6.66 ; 6.66$ \\
VAT & $\max$ & 2 & 0.08 & $0.2 ; 0.02 ; 0.04$ & $0.4 ; 0.13 ; 0.39$ & $0.38 ; 0.13 ; 0.37$ \\
OTIF & $\max$ & 5 & 10.67 & $73 ; 3 ; 2$ & $105 ; 0 ; 0$ & $105 ; 0 ; 0$ \\
VOF & $\max$ & 3 & 1.67 & $0 ; 0 ; 0$ & $5 ; 0 ; 0$ & $5 ; 0 ; 0$ \\
\hline
\end{tabular}


Table 14. Dynamic derived input data for decision algorithm

\begin{tabular}{lllllll}
\hline $\mathrm{c}_{\mathrm{k}}$ & $\mathrm{e}_{\mathrm{k}}$ & $\mathrm{w}_{\mathrm{k}}$ & $\sigma_{\mathrm{k}}$ & $\mathrm{a}_{0}(\mathrm{CS})$ & $\mathrm{a}_{1}(\mathrm{FS} 1)$ & $\mathrm{a}_{2}(\mathrm{FS} 2)$ \\
\hline $\mathrm{INV}$ & $\min$ & 3 & 81.83 & $1082 ; 336.8 ; 233.1$ & $951.5 ; 310.9 ; 52.70$ & $1009 ; 326.85 ; 156.8$ \\
LTB & $\min$ & 4 & 13.82 & $42.12 ; 8.32 ; 15.9$ & $21 ; 4 ; 11.8$ & $31.95 ; 7.06 ; 8.21$ \\
VAT & $\max$ & 2 & 0.39 & $0.18 ; 0.03 ; 0.12$ & $0.85 ; 0.1 ; 0.08$ & $0.6 ; 0.02 ; 0.09$ \\
OTIF & $\max$ & 5 & 12.01 & $61 ; 3 ; 12.5$ & $94.8 ; 5.12 ; 2$ & $93.69 ; 4.59 ; 1.88$ \\
VOF & $\max$ & 3 & 0.33 & $0 ; 0 ; 0$ & $0 ; 0 ; 1$ & $0 ; 0 ; 0$ \\
\hline
\end{tabular}

After calculating the net flows using the F-PROMETHEE algorithm following results can be obtained, see table 15 and figure 14 for visualization.

Table 15. Fuzzy net flows for the value stream alternatives under evaluation using static and dynamic data

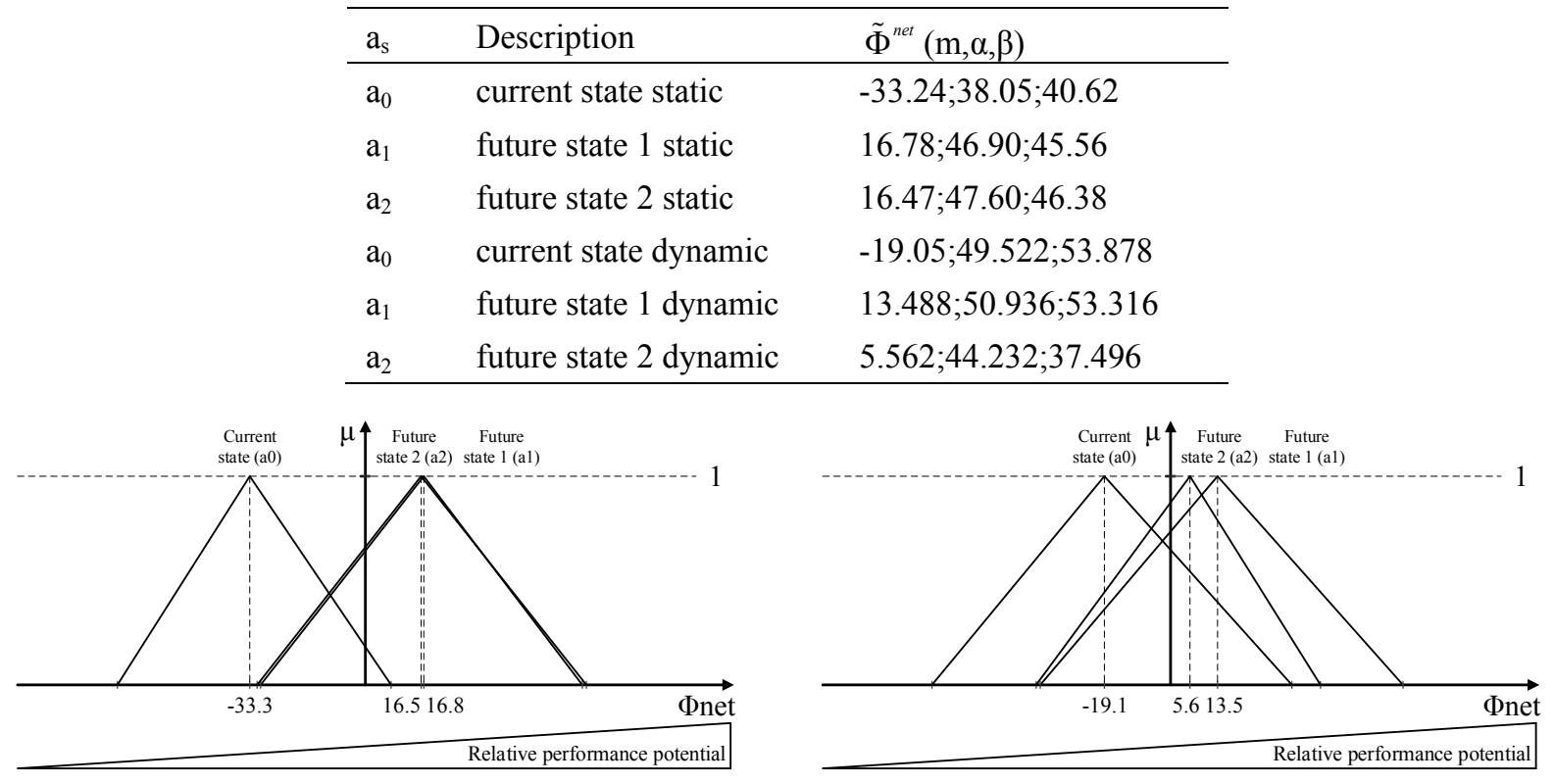

Figure 14. Results of the multidimensional evaluation using static (left) and dynamic (right) data

Both graphics show the relative advantageousness of the three system designs and the ranges of uncertainty included through variable input data for the current state as well as design uncertainties for both future states. In both cases it can be seen, that considering the middle values $\mathrm{m}$ both future states outrank the current state. Looking at the static evaluation data there is no significant difference in both future states, therefore no decision can be derived which alternative is better. Out of the dynamic evaluation it can be said that future state 1 has the highest net flow and represents the most suitable alternative design. Considering the relatively low complexity of the underlying production system, the effort for performing the dynamic quantification was very high but taken into account for comparing results. Following the proposed methodology after this evaluation and selection of future state 1 an implementation plan with concrete measures has to be developed, which will not be discussed further in this paper.

\section{Conclusions}

The comprehensive value stream optimization approach shown in this paper was developed to help getting more transparent results regarding the selection process of value stream alternatives, which are derived out of volatile production systems. The effects of proactively changing volatile production systems often are unknown and could underlie vast variations due to the planned outcome. The importance of a static or dynamic quantification showing current and possible future variability is emphasized to enrich management decisions by a wider spectrum of information and to foster the adoption of necessary system changes. Under inclusion of the fuzzy set theory three design alternatives (current state, future state 1 and future state 2) were evaluated in a case study taking into account five value stream KPIs. 


\section{References}

Abdulmalek, F. A., \& Rajgopal, J. (2007). Analyzing the benefits of lean manufacturing and value stream mapping via simulation: A process sector case study. Journal of Production Economics, 107(1). http://dx.doi.org/10.1016/j.ijpe.2006.09.009.

Abele, E., Eichhorn, N., \& Kuhn, S. (2007). Increase of productivity based on capability building in a learning factory. 11th International Conference on Production Engineering, Biograd, Croatia, 2007.

Abele, E., \& Reinhart, G. (2011). Future of production: challenges, fields of research, opportunities. Munich: Carl Hanser Verlag.

Al-Aomar, R. (2011). Handling multi-lean measures with simulation and simulated annealing. Journal of the Franklin Institute, 348(7). http://dx.doi.org/10.1016/j.jfranklin.2010.05.002 .

Azadeh, A., Seifoory M., \& Abbasi, M. (2007). Integration of simulation and fuzzy multi-attribute decision making for modelling and assessment of fuzzy parameters. Journal of Industrial and Systems Engineering, 6(4). http://dx.doi.org/10.1504/IJISE.2010.036029.

Banks, J., \& Gibson, R. (1997). Don't simulate when... 10 rules for determining when simulation is not appropriate. IEE Solutions, 29(9), 30-36.

Bellman, R. E., \& Zadeh, L. A. (1970). Decision making in a fuzzy environment. Management Science, 17(4), $141-164$.

Belton, V., \& Stewart, T. (2002). Multiple criteria decision making: An integrated approach. Boston: Kluwer Academic Publishers.

Bokranz, R., \& Landau, K. (2006). Productivity management of work systems: MTM field book. Stuttgart: Schaefer-Poeschel Verlag.

Boerkircher, M., \& Gamber, T. (2010). Simulation based value stream design - Approach for increasing value added potential in building materials industry. In G. Zuelch \& P. Stock (Eds.), Integrationsaspekte der Simulation: Technik, Organisation und Personal (pp. 405-412). Karlsruhe: KIT Scientific Publishing.

Braglia, M. F. M., \& Zammori, F. (2009). Uncertainty in value stream mapping analysis. Journal of Logistics Research and Applications, 12(6). http://dx.doi.org/10.1080/13675560802601559.

Brans, J. P., Mareschal, B., \& Vincke, P. (1984). PROMETHEE: A new family of outranking methods in multicriteria analysis. Journal of Operational Research, 477-490.

Brueggemann, H., \& Mueller, P. (2008). Digital value stream mapping. In M. Rabe (Ed.), 13. ASIM Fachtagung Simulation in Produktion und Logistik, Berlin, October 01-02, 2008 (pp. 575-584). Stuttgart: Fraunhofer IRB Verlag.

Cai, Y., \& You, J. (2008). Research on value stream analysis and optimization methods. Proceedings of the 4th International Conference on Wireless Communications, Networking and Mobile Computing. Dalian, China, October 12-14, 2008. http://dx.doi.org/10.1109/WiCom.2008.1521.

Caridi, M., \& Cavalieri, S. (2004). Multi-agent systems in production planning and control: An overview. Production Planning \& Control, 15(2). http://dx.doi.org/10.1016/S0925-5273(99)00097-3.

Cochran, J. K., \& Chen, H.-N. (2005). Fuzzy multi-criteria selection of object-oriented simulation software for production system analysis. Computers \& Operations Research. http://dx.doi.org/10.1016/S0305-0548(03)00209-0.

Chen, S. J., Hwang, C. L., \& Hwang, C. Z. (1992). Fuzzy Multible Attribute Decision Making: Methods and Applications (Lecture Notes in Economics and Mathematical Systems). New York: Springer-Verlag.

Cramér, H. (1946). Mathematical methods of statistics. USA: Princeton University Press.

Damm, H. (2006). Material flow in the center - Scalable overall concepts for prismatic powertrain components. Zeitschrift fuer Werkstatt und Betrieb, 9, 68-71.

Daniluk, D., \& Chisu, R. (2010). Simulation and emulation in the internet of things. In W. Guenther \& M. tenHompel (Eds.), Internet of things in intralogistics (pp. 147-169): Springer-Verlag.

Detty, R. B., \& Yingling, J. C. (2000). Quantifying benefits of conversion to lean manufacturing with discrete event simulation: A case study. Journal of Production Research, 38(2). http://dx.doi.org/10.1080/002075400189509. 
Domschke, W., \& Scholl, A. (2005). Fundamentals of business economics: An introduction out of a decision-oriented perspective. Berlin: Springer-Verlag.

Doolen, T. L., \& Hacker, M. E. (2005). A review of lean assessment in organizations: An exploratory study of lean practices by electronics manufacturers. Journal of Manufacturing Systems, 24(1). http://dx.doi.org/10.1016/S0278-6125(05)80007-X.

Driankov, D., Hellendorn, H., \& Reinfrank, M. (1993). An introduction to fuzzy control. Berlin: Springer-Verlag.

Erlach, K. (2010). Value stream design: The way to lean factory. Berlin: Springer-Verlag.

Evans, G. W., \& Alexander, S. M. (2007). Using multi-criteria modeling and simulation to achieve lean goals. In S. G. Henderson, B. Biller, M. H. Hsieh, J. Shortle, J. D. Tew, \& R. R. Barton (Eds.), Winter Simulation Conference 2007, Washington, D.C., USA, December 09-12, 2007 (pp. 1615-1623): IEEE. http://dx.doi.org/10.1109/WSC.2007.4419781.

Feld, W. M. (2001). Lean manufacturing: Tools, techniques and how to use them. Boca Raton: CRC Press.

Fente, J., Knutson, K., \& Schexnayder, C. (1999). Defining a beta distribution function for construction simulation. In P. A. Farrington, H. B. Nembhard, D. T. Sturrock, \& G. W. Evans (Eds.), 1999 Winter Simulation Conference, Proenix, USA, December 05-09, 1999 (pp. 1010-1015): IEEE. http://dx.doi.org/10.1109/WSC.1999.816813.

Geldermann, J., Sprengler, T., \& Rentz, O. (2000). Fuzzy outranking for environmental assessment. Case study: Iron and steel making industry. Fuzzy sets and systems, 115. http://dx.doi.org/10.1016/S0165-0114(99)00021-4.

Goumas, M., \& Lygerou, V. (2000). An extension of the promethee method for decision making in fuzzy environment. Journal of Operational Research, 123. http://dx.doi.org/10.1016/S0377-2217(99)00093-4.

Haemmerle, M., \& Rally, P. (2010). Increasing value creation: Results of data collection on the dissemination and refinement of methods for process optimization in production with a special focus on value stream mapping. Stuttgart: Fraunhofer Verlag.

Hobbs, D. P. (2004). Lean manufacturing implementation: A complete execution manual for any size manufacturer. Boca Raton: J. Ross Publishing.

Hwang, C., \& Yoon, K. (1981). Multiple attribute decision making: Methods and applications. Boston: Kluwer Academic Publishers.

Krafcic, J. F. (1988). Triumph of the lean production system. Sloan Management Review, 30(1), 41-52.

Lanza, G., \& Ude, J. (2010). Multidimensional evaluation of value added networks. CIRP Annals - Manufacturing Technology, 59. http://dx.doi.org/10.1016/j.cirp.2010.03.080.

Law, M. L., \& Kelton, D. Simulation modeling and analysis (3rd edn): Mcgraw-Hill Higher Education.

Lian, Y. H., \& van Landeghem, H. (2002). An application of simulation and value stream mapping in lean manufacturing. In A. Verbraeck \& W. Krug (Eds.), 14th European Simulation Symposium, Dresden, Germany, October 23-26, 2002 : SCS Europe Bvba and SCS International.

Lu, J. C., Yang, T., \& Wang, C. Y. (2011). A lean pull system design analysed by value stream mapping and multiple criteria decision making method under demand uncertainty. Journal of Computer Integrated Manufacturing, 24(3). http://dx.doi.org/10.1080/0951192X.2010.551283.

Marvel, J. H., \& Standridge, C. R. (2009). A simulation-enhanced lean design process. Journal of Industrial Engineering and Management, 2(1). http://dx.doi.org/10.3926/jiem.2009.v2n1.p90-113.

Maerz, L., Krug, H., Rose, O., \& Weigert, G. (2011). Simulation and optimization of production and logistics. Berlin: Springer-Verlag.

McDonald, T., van Aken, E. M., \& Rentes, A. F. (2002). Utilising simulation to enhance value stream mapping: A manufacturing case application. Journal of Logistics Research and Applications, 5(2). http://dx.doi.org/10.1080/13675560210148696.

Oeltjenbruns, H. (2000). Organization of production systems according to the toyota model. Dissertation. Shaker Verlag, Herzogenrath, Maastricht.

Ohno, T. (1982). How the toyota production system was created. Japanese Economic Studies, 4, 83-101.

Queiruga, D., Walther, G., Gonzales-Benito, J., \& Sprengler, T. (2008). Evaluation of sites for the location of weee recycling plants in Spain. Journal of Waste Management, 28. http://dx.doi.org/10.1016/j.wasman.2006.11.001. 
Robinson, S. (2004). Simulation: The practice of model development and use. Chichester, GB: John Wiley \& Sons Ltd.

Roessler, M. P., \& Abele, E. (2013). Uncertainty in the analysis of the overall equipment effectiveness on the shop floor. IOP Conference Series: Material Science and Engineering, 46(012019).

Rogalski, S. (2010). Tool for evaluating flexibility (ecoflex) used in mid-sized companies. wt Werkstattstechnik online, $3,120-124$.

Rother, M., \& Shook, J. (1999). Learning to see: Value-stream mapping to create value and eliminate muda. Lean Enterprise Institute.

Seyedhosseini, S. M., Taleghani, A. E., Makui, A., \& Ghoreyshi, S. M. (2013). Fuzzy value stream mapping in multiple production streams: A case study in a parts manufacturing company. Journal of Management Science and Engineering Management, 8(1). http://dx.doi.org/10.1080/17509653.2013.783190.

Standridge, C. R., \& Marvel, J. H. (2006). Why lean needs simulation. In L. F. Perrone, F. P. Wieland, J. Liu, B. G. Lawson, M. D. Nicol, \& R. M. Fujimoto (Eds.), Winter Simulation Conference 2006, Monterey, USA, December 03-06, 2006 (pp. 1907-1913): IEEE. http://dx.doi.org/10.1109/WSC.2006.322973.

Wolff, M. (2013). Method for value stream optimization using simulative evaluation of action alternatives. Dissertation. Technical University Darmstadt, Darmstadt.

Womack, J. P., Jones, D. T., \& Roos, D. (1990). The machine that changed the world: The story of Lean Production. New York: Free Press.

Zadeh, L. A. (1965). Fuzzy sets. Journal of Information and Control, 8(3), 338-353.

Zimmermann, H. J., \& Gutsche, L. (1991). Multi-criteria analyse. Berlin: Springer-Verlag. 